\title{
ANÁLISE DA INFLUÊNCIA DO MÉTODO DE RESFRIAMENTO SOBRE A RESISTÊNCIA RESIDUAL DO CONCRETO SUBMETIDO A ALTAS TEMPERATURAS
}

\author{
BUENO, LISIANE \\ Engenheira Civil \\ UTFPR \\ PR; Brasil \\ lisianebueno@hotmail.com \\ MAZER, WELLINGTON \\ Professor, DSc \\ UTFPR \\ PR; Brasil \\ wmazer@utfpr.edu.br
}

\author{
WICZICK, LUCIENE F. S. \\ Professora, MEng \\ UTFPR \\ PR; Brasil \\ luciene@utfpr.edu.br
}

\section{RESUMO}

A ocorrência de um incêndio, além da possibilidade de provocar a perda de vidas humanas, produz danos às estruturas de concreto armado. O método mais comum para o combate a incêndios é através da utilização da água para resfriamento do material e controle das chamas. No entanto este resfriamento pode provocar um choque térmico na estrutura e agravar os danos estruturais. O presente trabalho tem o objetivo de analisar o efeito dos métodos de extinção de incêndio na perda de resistência do concreto após este ser submetido à altas temperaturas. Amostras de concreto foram submetidas às temperaturas de $400^{\circ} \mathrm{C}, 600^{\circ} \mathrm{C}$ e $800^{\circ} \mathrm{C}$, e resfriadas com três métodos: temperatura ambiente, carga de extintor de gás carbônico e submersas em um recipiente com água. Foi verificado que o método utilizado para o resfriamento não demonstrou ter tanta influência na resistência residual do concreto quanto a exposição a temperaturas maiores. As amostras aquecidas a $400^{\circ} \mathrm{C}$ apresentaram uma perda média na resistência de $18,2 \%$, enquanto que as aquecidas a $600^{\circ} \mathrm{C}$ apresentaram uma perda média de $44 \%$ e as aquecidas a $800^{\circ} \mathrm{C}$ tiveram perda média de $84,4 \%$ comparados com o concreto de referência.

Palavras-chave: concreto, incêndio, resfriamento, alta temperatura.

\section{ABSTRACT}

The occurrence of a fire, besides the possibility of causing the loss of human life, causes damage to reinforced concrete structures. The most common method for firefighting is through the use of water for material cooling and flame control. However, this cooling can cause a thermal shock to the structure and aggravate structural damage. The present work aims to analyze the effect of fire extinguishing methods on loss of concrete resistance after it is exposed to high temperatures. Concrete samples were exposed to temperatures of $400^{\circ} \mathrm{C}, 600^{\circ} \mathrm{C}$ and $800^{\circ} \mathrm{C}$, and cooled with three methods: room temperature, carbon dioxide extinguisher charge and submerged in a container with water. It was found that the method used for cooling did not show as much influence on the residual strength of the concrete as the exposure to higher temperatures. Samples heated at $400^{\circ} \mathrm{C}$ had an average loss in strength of $18.2 \%$, while samples heated at $600^{\circ} \mathrm{C}$ had an average loss of $44 \%$ and samples heated at $800^{\circ} \mathrm{C}$ had an average loss of $84.4 \%$ compared with reference concrete.

Keywords: concrete, fire, cooling, high temperature.

\section{INTRODUÇÃO}

A prevenção e combate à incêndios em edificações ainda não é um tema fortemente estabelecido no dia a dia e na cultura dos brasileiros, mas é um assunto de extrema importância e que necessita de mais atenção por parte dos profissionais da área de construção civil e da população em geral. Pois além da possibilidade de perda de vidas humanas e prejuízos materiais, a ocorrência de um incêndio resulta em danos na estrutura das edificações, acarretando em altos custos de recuperação e reconstrução. 
Nota-se que após o fogo ter atingido maiores proporções, o meio normalmente utilizado para a sua extinção é o uso de água, pois esta ajuda a reduzir a temperatura do material em chamas. Entretanto, há a preocupação de que esse método de resfriamento de edificações em situações de incêndio possa aumentar os danos resultantes em estruturas de concreto, visto que a elevada temperatura a que a estrutura está submetida devido ao fogo é rapidamente resfriada, levantando a dúvida se o choque térmico e a forma de resfriamento utilizado no combate ao incêndio pode afetar ainda mais a resistência residual do concreto. O presente estudo tem por objetivo analisar o efeito dos métodos de extinção de incêndio, que utilizam o resfriamento no combate às chamas, na perda de resistência do concreto após este ser submetido à altas temperaturas.

\section{REVISÃO DA LITERATURA}

Para um melhor entendimento sobre incêndios em edificações é importante conhecer os conceitos principais de fogo e incêndio, as formas de extinção do fogo e o efeito das altas temperaturas nos materiais.

\subsection{Conceitos básicos sobre fogo e incêndio}

Segundo a Norma de Procedimento Técnico - NPT 003 - Terminologia de segurança contra incêndio, "fogo é uma reação química de oxidação (processo de combustão), caracterizada pela emissão de calor, luz e gases tóxicos. Para que o fogo exista, é necessário a presença de quatro elementos: combustível, comburente (normalmente o oxigênio), calor e reação em cadeia" (CBPMPR, 2014). Ainda de acordo com a NPT 003, "incêndio é o fogo sem controle, intenso, o qual causa danos e prejuízos à vida, ao meio ambiente e ao patrimônio” (CBPMPR, 2014).

A NBR 14432 (ABNT, 2001) define incêndio natural como a variação de temperatura que simula o incêndio real, sendo função da geometria, ventilação, características térmicas dos elementos de vedação e da carga de incêndio específica. Esta norma também expõe o conceito de incêndio-padrão como a elevação padronizada de temperatura em função do tempo, definida pela equação 1 , onde t é o tempo em minutos, $\theta_{\mathrm{g}}$ é a temperatura dos gases, em graus Celsius no instante $\mathrm{t}, \theta_{0}$ é a temperatura do ambiente antes do início do aquecimento, em graus Celsius, geralmente considerada como sendo igual a $20^{\circ} \mathrm{C}$.

$$
\theta_{\mathrm{g}}=\theta_{0}+345 \log (8 \mathrm{t}+1)
$$

A figura 1 mostra a curva para o incêndio-padrão definido na NBR 14432 (ABNT, 2001), considerando a temperatura do ambiente como $20^{\circ} \mathrm{C}$. Segundo Seito et al. (2008), a curva de incêndio padrão recomendada pela norma brasileira é baseada na norma internacional ISO 834 (1994), que considera materiais celulósicos como combustível.

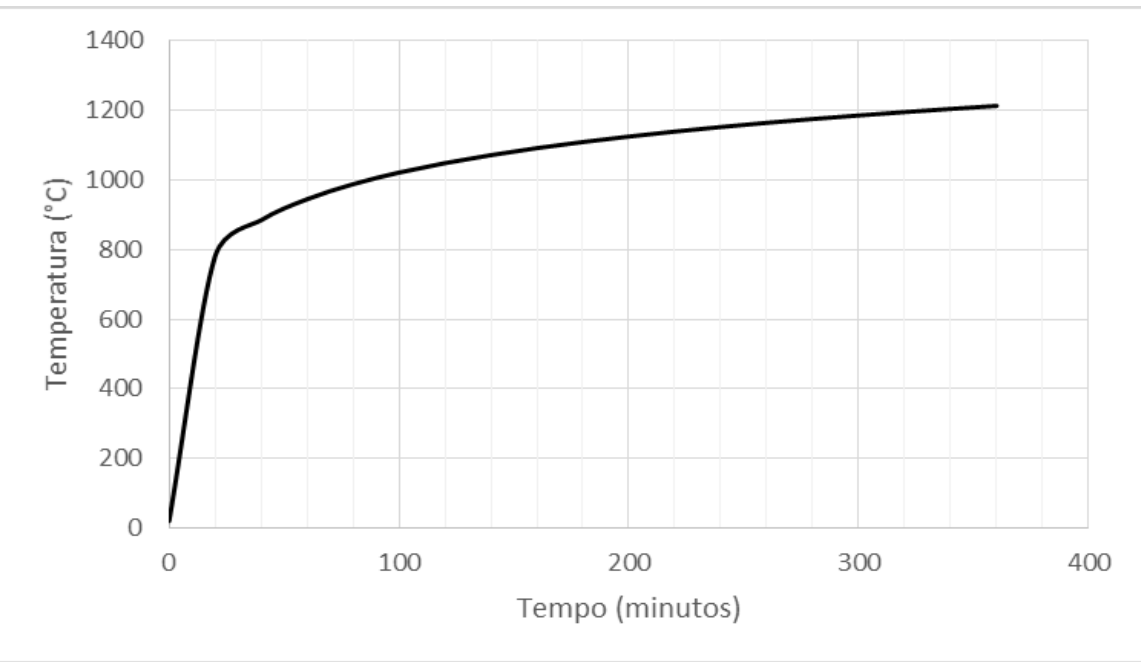

Figura 1: Curva para o incêndio-padrão, considerando temperatura inicial de $20^{\circ} \mathrm{C}$

Nota-se que a equação do incêndio-padrão não abrange a fase de resfriamento e extinção do fogo, considerando somente a elevação da temperatura de forma padronizada. O objetivo principal da utilização dessa curva-padrão é 
fornecer parâmetros de projeto, a fim de garantir a resistência da estrutura em situação de incêndio, evitando o colapso estrutural da edificação durante o tempo mínimo pré-estabelecido por normas.

O tempo requerido de resistência ao fogo (TRRF) estabelecido pela NBR 14432 (ABNT, 2001), é o tempo mínimo que um elemento construtivo deve resistir quando sujeito ao incêndio-padrão. Segundo Silva (2008), através da associação do TRRF com a curva para o incêndio-padrão, é possível determinar a temperatura média no elemento estrutural similar à temperatura encontrada no incêndio real. O TRRF pode ser determinado por meio de tabelas, conforme especificado pela NBR 14432 (ABNT, 2001), ou através de equações como o procedimento proposto por Silva (2008).

\subsubsection{Meios de extinção do fogo}

De acordo com Seito et al. (2008), a diferença entre um pequeno e um grande incêndio está na propagação e intensidade das chamas. Em geral, os incêndios começam com um pequeno foco, fácil de controlar. Por isso é importante o conhecimento dos métodos de extinção do fogo, que consistem em inibir cada um dos elementos presentes na reação de combustão a fim de se evitar que o fogo atinja grandes proporções, causando maiores danos. Dentre os meios de extinção do fogo, encontram-se:

- $\quad$ Retirada do combustível: retirar do local o material (combustível) que está pegando fogo.

- $\quad$ Abafamento: eliminar o oxigênio (comburente) da reação, por meio do abafamento do fogo.

- $\quad$ Resfriamento: reduzir a temperatura (calor) do material em chamas

- $\quad$ Reação em cadeia: o calor irradiado das chamas atinge o combustível, este é decomposto em partículas menores que se combinam com o oxigênio e queimam, irradiando outra vez calor para o combustível, formando assim um ciclo constante. A quebra da reação em cadeia impede que a reação seja autossustentável.

O emprego de extintores tem o objetivo de combater princípios de incêndio, e faz parte do sistema básico de segurança contra incêndio em edificações, tendo como características principais a portabilidade, facilidade de uso, manejo e operação (SEITO et al.,2008).

\subsection{Efeito das altas temperaturas no concreto}

Segundo Mehta e Monteiro (2008), o concreto não é um material combustível e não emite gases tóxicos quando exposto a altas temperaturas. Entretanto, o comportamento real de uma estrutura de concreto submetido à altas temperaturas é resultado de diversos fatores que interagem simultaneamente, sendo difícil uma análise precisa. De acordo com os autores, alguns fatores importantes na resposta do concreto ao fogo são a composição do concreto, a permeabilidade, o tamanho do elemento e a taxa de aumento da temperatura.

De acordo com Fernandes et al. (2017), a zona de transição, que é a interface entre os agregados e a pasta de cimento, possui uma maior fragilidade devido à presença de vazios e fissuras na região, além de C-S-H pouco cristalino e cristais secundários de portlandita e etringita. $\mathrm{O}$ aquecimento do concreto resulta em uma expansão térmica diferencial entre o agregado e a pasta de cimento, uma vez que a pasta de cimento retrai quando aquecida e os agregados expandem, resultando em fissuras. Os autores verificaram que a degradação do concreto está diretamente ligada com as características do material e com o processo de aquecimento.

Silva (2009) avaliou a influência da temperatura na resistência residual de concretos usuais empregados na construção civil e constatou que com o aumento da temperatura, a resistência à compressão axial diminui. A autora obteve resultados com perda de resistência superiores a $50 \%$ para temperaturas entre $400^{\circ} \mathrm{C}$ e $900^{\circ} \mathrm{C}$ e valores de resistência à compressão praticamente nulos para os corpos de prova submetidos a temperaturas a partir de $900^{\circ} \mathrm{C}$. Além disso a autora verificou uma redução do módulo de elasticidade mais acentuada que a redução da resistência à compressão axial em função da temperatura, redução de massa e aumento da porosidade devido à perda de água na microestrutura com o aumento da temperatura.

Lorenzon (2014) analisou a resistência residual de concretos expostos à diferentes temperaturas $\left(300^{\circ} \mathrm{C}, 500^{\circ} \mathrm{C} \mathrm{e}\right.$ $\left.800^{\circ} \mathrm{C}\right)$, tempos de exposição $(30$ minutos, 60 minutos e 90 minutos) e modos de resfriamento (rápido e lento). A autora verificou perdas consideráveis da resistência à compressão para as amostras expostas a altas temperaturas, mas os diferentes tipos de resfriamento adotados (resfriamento com água fria e na temperatura ambiente) apresentaram poucas alterações sobre a redução da resistência residual do concreto. Sousa (2009) avaliou a influência do tipo de resfriamento em corpos de prova de concreto, sendo as amostras resfriadas lentamente à temperatura ambiente e bruscamente sendo 
imersas em água por 30 minutos. $\mathrm{O}$ autor verificou que os tipos de resfriamento estudados exerceram praticamente a mesma influência sobre as propriedades mecânicas do concreto analisado.

\section{MATERIAIS E MÉTODOS}

Utilizou-se amostras de concreto cilíndricas, com tamanho 10 × $20 \mathrm{~cm}$, executadas com um traço padrão de concreto em massa de 1:2,5:3,2:0,6, utilizando-se cimento CP V-ARI, areia média, brita I, e consumo de cimento de $300 \mathrm{~kg} / \mathrm{m}^{3}$. O concreto foi feito em uma betoneira com capacidade de 120 litros.

As amostras de concreto foram submetidas às temperaturas de $400^{\circ} \mathrm{C}, 600^{\circ} \mathrm{C}$ e $800^{\circ} \mathrm{C}$ em forno tipo mufla com o objetivo de simular temperaturas de incêndio, e em seguida foram resfriadas utilizando-se três métodos diferentes: água, gás carbônico $\left(\mathrm{CO}_{2}\right)$ e resfriamento natural, analisando-se a resistência do concreto após esses procedimentos. Essas temperaturas foram escolhidas por serem temperaturas facilmente atingidas na primeira meia hora de um incêndiopadrão, conforme pode ser visualizado na curva da figura 1. O pó químico não foi utilizado no presente estudo devido ao fato de não possuir a função de resfriamento, agindo na extinção do fogo somente por abafamento.

Foram utilizadas quatro amostras de concreto para cada método de resfriamento e para cada temperatura analisada, conforme apresentado na tabela 1. A utilização de quatro corpos de prova para cada método se deve ao fato deste ser o número mínimo de amostras calculado estatisticamente para se estar dentro do intervalo de $95 \%$ de certeza dos resultados.

Tabela 1 - Quantidade de corpos de prova testados

\begin{tabular}{c|c|c|c}
\hline \multirow{2}{*}{$\begin{array}{c}\text { Método de } \\
\text { resfriamento }\end{array}$} & \multicolumn{3}{|c}{ Temperatura } \\
\cline { 2 - 4 } & $400^{\circ} \mathrm{C}$ & $600^{\circ} \mathrm{C}$ & $800^{\circ} \mathrm{C}$ \\
\hline Natural & $4 \mathrm{CP}$ & $4 \mathrm{CP}$ & $4 \mathrm{CP}$ \\
\hline Água & $4 \mathrm{CP}$ & $4 \mathrm{CP}$ & $4 \mathrm{CP}$ \\
\hline $\mathrm{CO}_{2}$ & $4 \mathrm{CP}$ & $4 \mathrm{CP}$ & $4 \mathrm{CP}$ \\
\hline Total & $12 \mathrm{CP}$ & $12 \mathrm{CP}$ & $12 \mathrm{CP}$ \\
\hline
\end{tabular}

Para a execução das amostras, primeiramente verificou-se a umidade da areia através das medidas da massa inicial e massa seca, obtendo-se uma umidade de 10\%. Depois de as quantidades dos materiais serem separadas, fez-se primeiro a imprimação da betoneira, com argamassa do mesmo traço utilizado. Em seguida, os materiais foram adicionados na betoneira na seguinte ordem: agregado graúdo, uma parte da água, agregado miúdo, cimento e por último o restante da água. Após a mistura estar homogênea, os corpos de prova foram moldados com o preenchimento de concreto em duas camadas, aplicando-se 12 golpes com a haste de socamento em cada camada.

Depois de 24 horas, os corpos de prova foram desmoldados e colocados em câmara úmida para a cura por 28 dias. Após esse tempo de cura, as amostras foram retiradas da câmara úmida e armazenadas em local seco. Depois de secas, as amostras foram inseridas em forno elétrico tipo mufla com temperatura máxima de $1200^{\circ} \mathrm{C}$. Foram inseridas duas de cada vez para as temperaturas de $400^{\circ} \mathrm{C}$ e $600^{\circ} \mathrm{C}$ e uma amostra de cada vez para a temperatura de $800^{\circ} \mathrm{C}$, como mostrado na figura 2. As amostras ficaram expostas à temperatura desejada por 30 minutos, ou seja, as amostras foram inseridas na mufla, esta foi ligada e após estabilizar na temperatura desejada contou-se 30 minutos. Não foi verificada a taxa de aumento de temperatura da mufla, pois procurou-se analisar os efeitos do resfriamento nas amostras após estas ficarem submetidas às temperaturas desejadas durante um mesmo intervalo de tempo.

Definiu-se o tempo de 30 minutos para as amostras ficarem expostas à temperatura desejada por ser o tempo requerido de resistência ao fogo (TRRF) mínimo estabelecido pela norma NBR 14432 (ABNT, 2001) na tabela A.1, uma vez que o objetivo do presente estudo é avaliar a perda da resistência devido ao resfriamento, e não o tempo de exposição da amostra às altas temperaturas. 


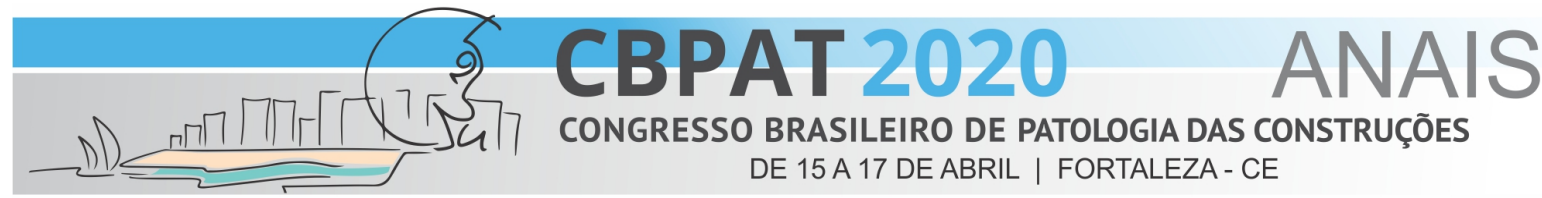

ISBN 978-65-86819-05-2
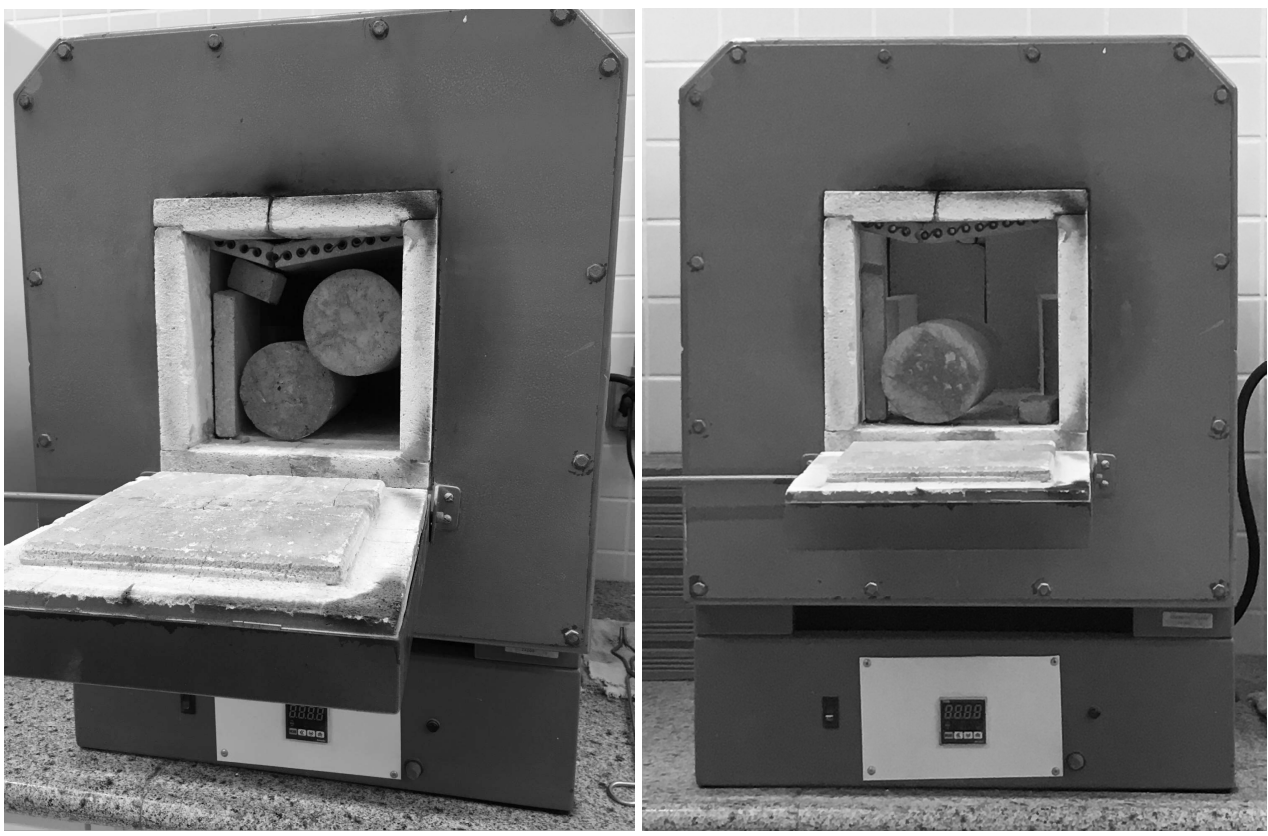

Figura 2: Amostras inseridas para aquecimento na mufla

Para o método de resfriamento natural, as amostras foram retiradas da mufla e deixadas para resfriar à temperatura ambiente. Para o método de resfriamento com $\mathrm{CO}_{2}$, as amostras foram retiradas da mufla, posicionadas no chão, em cima de uma cerâmica e imediatamente resfriadas com uma carga de extintor de CO2 de $9 \mathrm{~kg}$, conforme mostrado na figura 3.

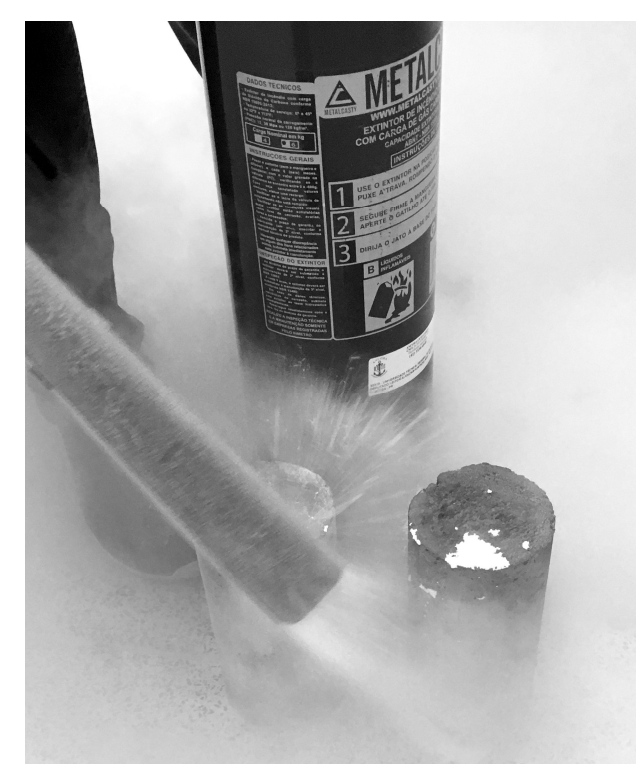

Figura 3: Resfriamento utilizando extintor de $\mathrm{CO}_{2}$

Para o método de resfriamento com água, as amostras foram retiradas da mufla e inseridas em um recipiente metálico contendo água (figura 4), ficando submersas até que resfriassem a ponto de se poder retirá-las com a mão. Para a temperatura de $400^{\circ} \mathrm{C}$, as amostras ficaram submersas em água por aproximadamente 15 minutos, para a temperatura de $600^{\circ} \mathrm{C}$ as amostras ficaram por aproximadamente 30 minutos submersas e para a temperatura de $800^{\circ} \mathrm{C}$ ficaram em contato com a água por aproximadamente uma hora. Os recipientes metálicos utilizados possuem $25 \mathrm{~cm}$ de diâmetro e $31 \mathrm{~cm}$ de altura, e foram enchidos com aproximadamente 11 litros de água. 

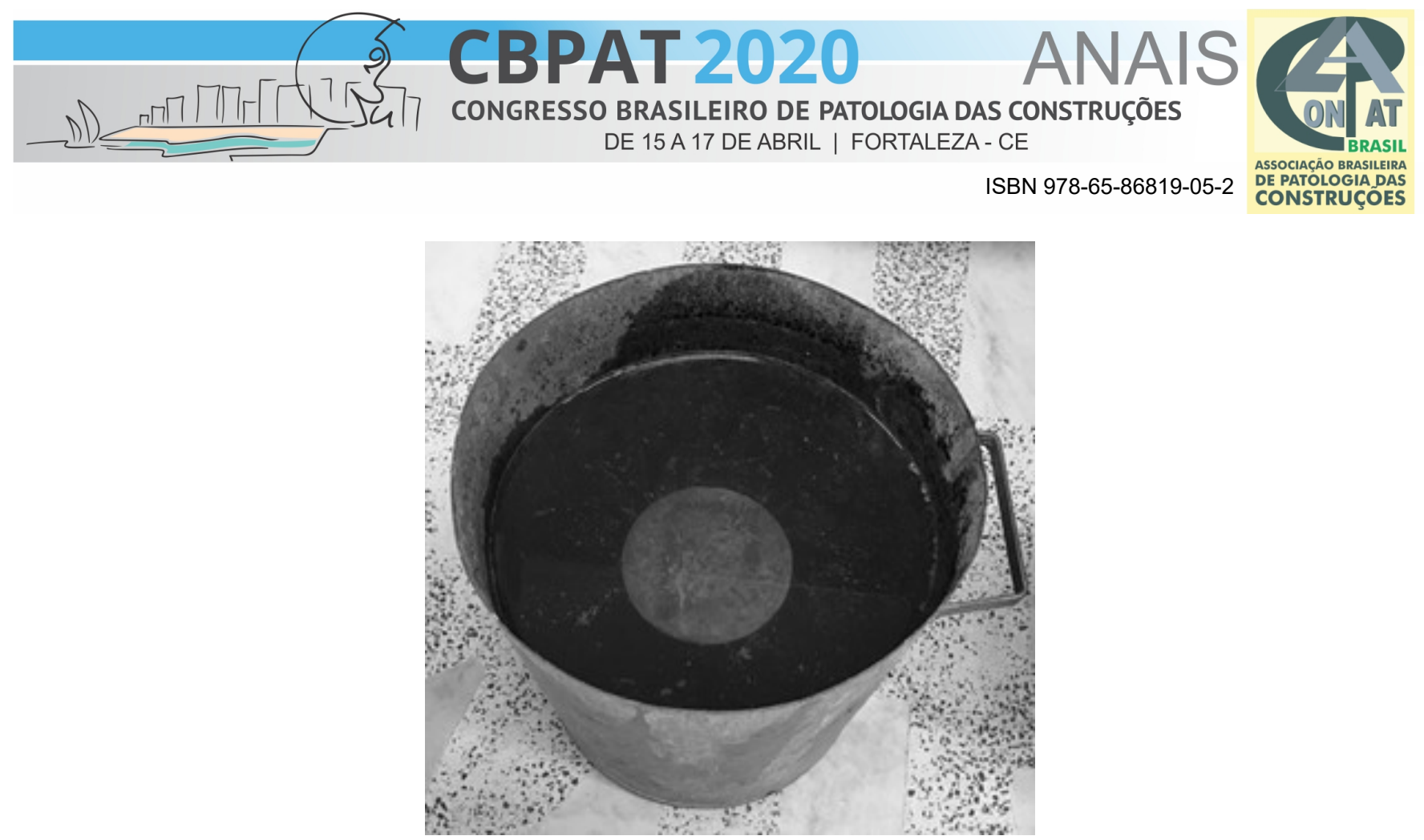

Figura 4: Resfriamento utilizando recipiente metálico com água

Aguardou-se até que todas as amostras estivessem totalmente resfriadas para a realização dos testes de resistência à compressão, que foram executados em prensa DL30 com carga máxima de 30 toneladas, como apresentado na figura 5.

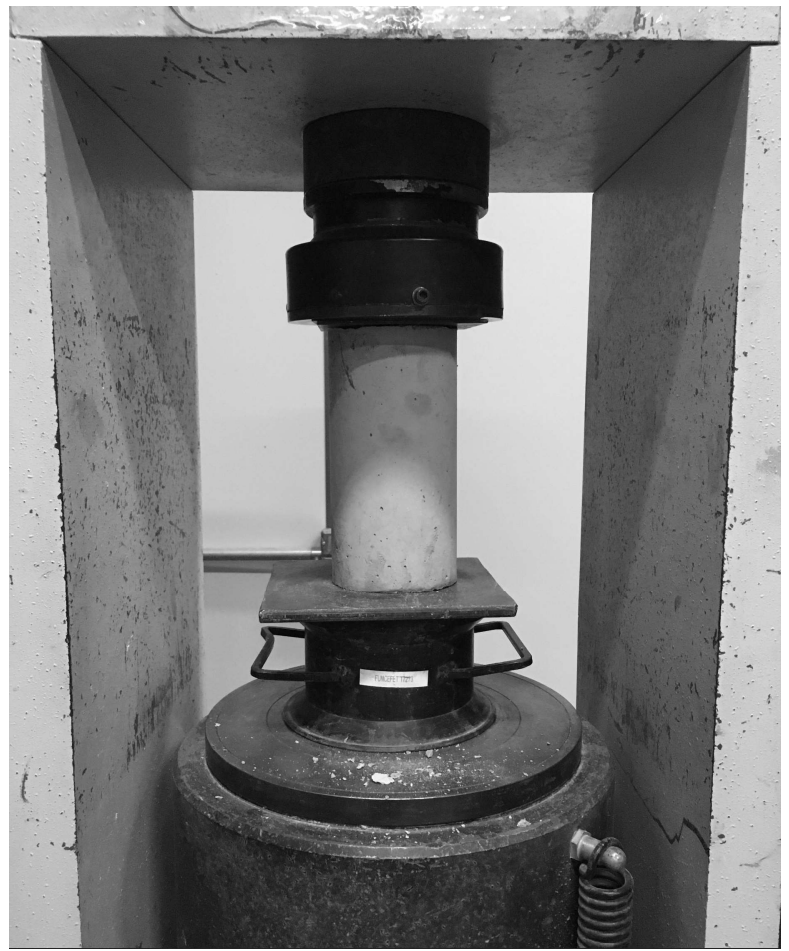

Figura 5: Teste de resistência à compressão realizado nas amostras depois de resfriadas

\section{RESULTADOS E DISCUSSÃO}

A resistência de referência foi verificada aos 28 dias em 4 corpos de prova, obtendo-se um valor médio de resistência igual a 18,8 $\mathrm{MPa}$ e desvio padrão igual a $0,9 \mathrm{MPa}$. Os valores de resistência à compressão axial obtidos após o aquecimento e resfriamento dos corpos de prova estão apresentados na tabela 2. 
Tabela 2 - Valores de resistência à compressão obtidos para as amostras

\begin{tabular}{|c|c|c|c|c|c|c|c|c|}
\hline \multirow{2}{*}{$\begin{array}{c}\text { Temperatura } \\
\left({ }^{\circ} \mathrm{C}\right)\end{array}$} & \multirow[b]{2}{*}{ Resfriamento } & \multicolumn{4}{|c|}{ Resistência (MPa) } & \multirow{2}{*}{$\begin{array}{l}\text { Resistência } \\
\text { média }(\mathrm{MPa})\end{array}$} & \multirow{2}{*}{$\begin{array}{l}\text { Desvio } \\
\text { padrão } \\
(\mathrm{MPa})\end{array}$} & \multirow{2}{*}{$\begin{array}{c}\text { Coeficiente } \\
\text { de variação } \\
(\%)\end{array}$} \\
\hline & & CP1 & $\mathrm{CP} 2$ & $\mathrm{CP} 3$ & $\mathrm{CP} 4$ & & & \\
\hline Referência & - & 20,1 & 18,7 & 18,7 & 17,9 & 18,8 & 0,9 & 5,0 \\
\hline \multirow{3}{*}{400} & Natural & 12,8 & 13,6 & 13,3 & 18,6 & 14,6 & 2,7 & 18,7 \\
\hline & $\mathrm{CO}_{2}$ & 13,0 & 14,2 & 15,5 & 22,5 & 16,3 & 4,3 & 26,2 \\
\hline & Água & 14,0 & 15,2 & 16,1 & 16,2 & 15,4 & 1,0 & 6,7 \\
\hline \multirow{3}{*}{600} & Natural & 12,1 & 12,9 & 8,1 & 5,8 & 9,7 & 3,3 & 34,2 \\
\hline & $\mathrm{CO}_{2}$ & 8,1 & 13,6 & 8,0 & 12,9 & 10,6 & 3,0 & 28,4 \\
\hline & Água & 12,6 & 10,9 & 8,6 & 13,2 & 11,3 & 2,1 & 18,5 \\
\hline \multirow{3}{*}{800} & Natural & 3,3 & 2,3 & 2,2 & 2,4 & 2,5 & 0,5 & 19,5 \\
\hline & $\mathrm{CO}_{2}$ & 2,5 & 2,6 & 2,1 & 2,6 & 2,4 & 0,3 & 10,5 \\
\hline & Água & 3,6 & 3,6 & 4,3 & 3,8 & 3,8 & 0,4 & 9,4 \\
\hline
\end{tabular}

A figura 6 apresenta as resistências médias para cada método de resfriamento em função da temperatura que as amostras foram aquecidas, onde é possível observar que o método de resfriamento natural, ou seja, à temperatura ambiente, apresentou as menores resistências médias, em geral. Além disso, pode-se verificar também que o resfriamento rápido com a utilização de água não apresentou as menores resistências médias para as amostras. Esse fato não era esperado, pois acreditava-se que esse método de resfriamento rápido do concreto poderia afetar negativamente a resistência por conta do choque térmico.

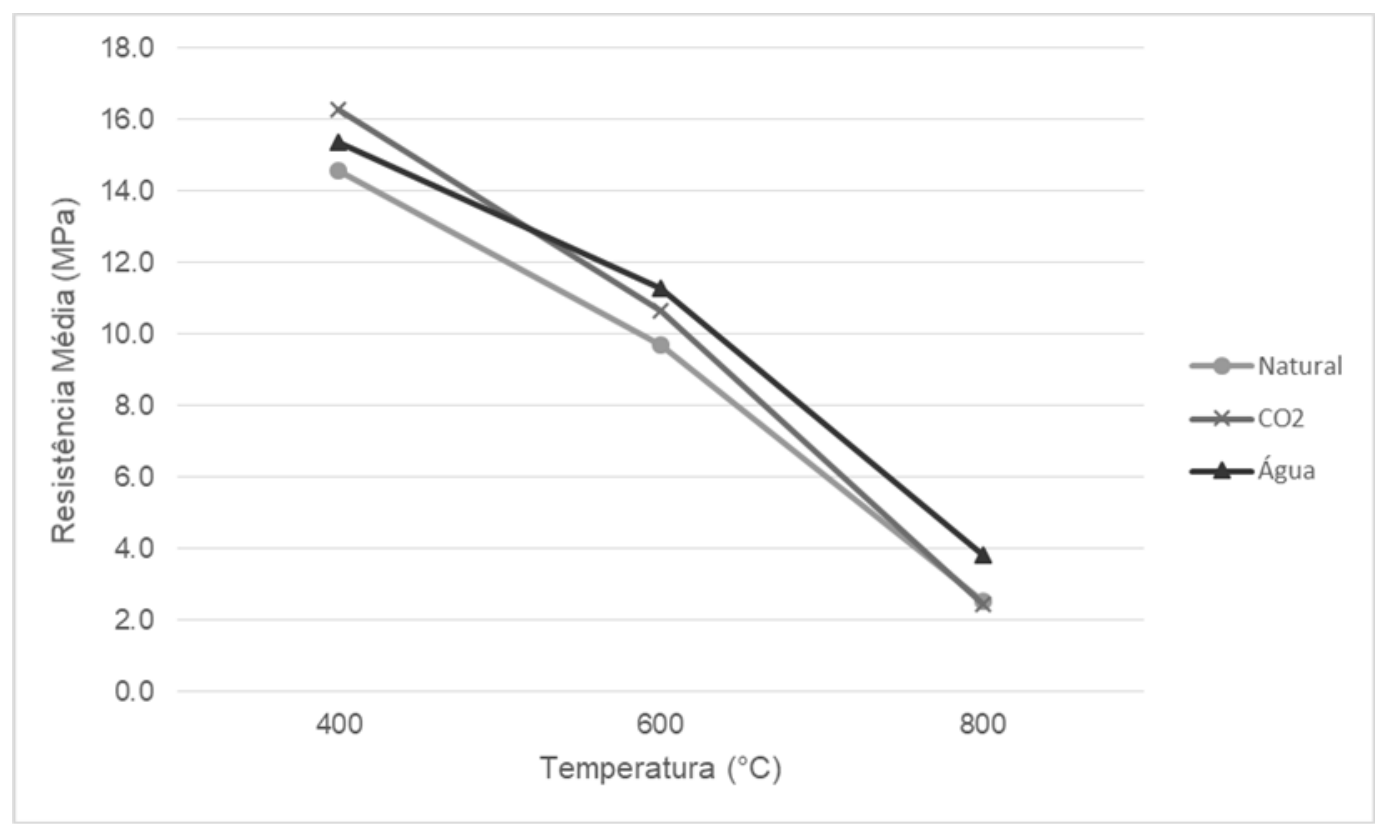

Figura 6: Resistência média em função da temperatura, para cada método de resfriamento

Os resultados obtidos seguem uma tendência semelhante ao estudo de Sousa (2009), que também obteve resistências residuais maiores para resfriamento brusco em alguns casos. O autor realizou ensaios de microscopia eletrônica de varredura e verificou alterações morfológicas nos corpos de prova resfriados com água, indicando uma reidratação do concreto após o aquecimento.

As perdas percentuais de resistência, em valores absolutos (para os resfriamentos natural, $\mathrm{CO}_{2}$ e água), estão apresentadas na tabela 3. Pode-se verificar que os métodos de resfriamento não demonstraram ter tanta influência no decréscimo de resistência das amostras de concreto quanto o aumento da temperatura. 
Tabela 3 - Valores médios das perdas percentuais nas resistências residuais dos corpos de prova

\begin{tabular}{|c|c|c|c|}
\hline Temperatura $\left({ }^{\circ} \mathrm{C}\right)$ & Resfriamento & Resistência média (MPa) & Perda de resistência (\%) \\
\hline \multicolumn{2}{|c|}{ Referência } & 18,8 & - \\
\hline \multirow{3}{*}{400} & Natural & 14,6 & $22,7 \%$ \\
\hline & $\mathrm{CO}_{2}$ & 16,3 & $13,4 \%$ \\
\hline & Água & 15,4 & $18,4 \%$ \\
\hline \multirow{3}{*}{600} & Natural & 9,7 & $48,4 \%$ \\
\hline & $\mathrm{CO}_{2}$ & 10,6 & $43,5 \%$ \\
\hline & Água & 11,3 & $40,0 \%$ \\
\hline \multirow{3}{*}{800} & Natural & 2,5 & $86,6 \%$ \\
\hline & $\mathrm{CO}_{2}$ & 2,4 & $87,1 \%$ \\
\hline & Água & 3,8 & $79,7 \%$ \\
\hline
\end{tabular}

Para poder afirmar, estatisticamente, se o método de resfriamento influencia a resistência do concreto, realizou-se a análise da variância (ANOVA) e o teste de Tukey, a fim de se comparar as médias das resistências residuais obtidas. Através do teste de variância constatou-se a existência de diferença estatística em algum dos dados analisados. Com isso, realizou-se o teste de Tukey, sendo possível verificar quais métodos são estatisticamente iguais. Os resultados dessa análise estão apresentados na tabela 4, onde as letras iguais indicam que não houveram diferenças estatísticas significativas entre si. Observa-se que não há diferença entre os métodos de resfriamento, e que apesar de haver uma porcentagem absoluta da perda de resistência média para as amostras aquecidas a $400^{\circ} \mathrm{C}$, não se pode afirmar que a temperatura de $400^{\circ} \mathrm{C}$ teve efeito significativo na perda de resistência do concreto estudado, uma vez que as resistências médias obtidas são estatisticamente iguais à resistência de referência. Já as temperaturas de $600^{\circ} \mathrm{C}$ e $800^{\circ} \mathrm{C}$ demostraram ter efeito na perda de resistência dos corpos de prova testados.

Tabela 4 - Resistências médias estatisticamente iguais

\begin{tabular}{|c|c|c|c|c|c|c|c|c|c|}
\hline $\begin{array}{c}\text { Temperatura } \\
\left({ }^{\circ} \mathrm{C}\right)\end{array}$ & Resfriamento & $\begin{array}{l}\text { Resistência } \\
\text { Média (MPa) }\end{array}$ & & & & & & & \\
\hline \multicolumn{2}{|c|}{ Referência } & 18,8 & A & & & & & & \\
\hline \multirow{3}{*}{400} & Natural & 14,6 & A & B & & & & & \\
\hline & $\mathrm{CO}_{2}$ & 16,3 & A & $\mathrm{B}$ & $\mathrm{C}$ & & & & \\
\hline & Água & 15,4 & $\mathrm{~A}$ & $\bar{B}$ & $\mathrm{C}$ & D & & & \\
\hline \multirow{3}{*}{600} & Natural & 9,7 & & $\mathrm{~B}$ & & & $\mathrm{E}$ & & \\
\hline & $\mathrm{CO}_{2}$ & 10,6 & & $\mathrm{~B}$ & & D & $\mathrm{E}$ & $\mathrm{F}$ & \\
\hline & Água & 11,3 & & B & $\mathrm{C}$ & $\mathrm{D}$ & $\mathrm{E}$ & $\mathrm{F}$ & \\
\hline \multirow{3}{*}{800} & Natural & 2,5 & & & & & & & $\mathrm{G}$ \\
\hline & $\mathrm{CO}_{2}$ & 2,4 & & & & & & & $\mathrm{G}$ \\
\hline & Água & 3,8 & & & & & & & $\mathrm{G}$ \\
\hline
\end{tabular}

Não foi verificado se o tempo de exposição à essas temperaturas contribuem ainda mais para a redução da resistência residual do concreto. Lorenzon (2014) verificou em seu estudo que a cada meia hora a mais expostos às altas temperaturas, os corpos de prova apresentaram resistências à compressão quase $24 \%$ menores.

Além da verificação da resistência residual do concreto, analisou-se também alguns aspectos como a formação de fissuras nas amostras, a forma que ocorreu a ruptura e se o método utilizado efetivamente resfriava o concreto. Durante a realização dos testes, observou-se que a utilização da água resfriou as amostras em um tempo relativamente rápido, considerando-se a temperatura com que saiam da mufla. Entretanto, a utilização do extintor de $\mathrm{CO}_{2}$ não resfriou as amostras de maneira rápida. Constatou-se a formação de gelo na parte superior dos corpos de prova aquecidos, que evaporou rapidamente. Mas pelo fato de o concreto ser um mal condutor de calor, o tempo de exposição ao $\mathrm{CO}_{2}$ não foi suficiente para resfriar o concreto de maneira rápida. Portanto, as amostras resfriadas com a carga de gás carbônico tiveram um resfriamento semelhante ao natural (temperatura ambiente). Verifica-se com isso, que a utilização de carga de gás carbônico no combate à incêndios simula o abafamento para extinção do fogo e não apresenta choque térmico na estrutura, uma vez que o gás não demonstrou capacidade de resfriamento dos corpos de prova.

Com relação à formação de fissuras, para as amostras aquecidas a $400^{\circ} \mathrm{C}$ e $600^{\circ} \mathrm{C}$ não se observou a formação visível de muitas fissuras. Já para as amostras aquecidas a $800^{\circ} \mathrm{C}$, observou-se uma grande formação de fissuras para o resfriamento natural e o com a carga de gás carbônico, conforme mostrado nas figuras 7 e 8 . Verificou-se também, que 
essas fissuras aumentaram com o tempo, ou seja, desde o momento em que foram retiradas da mufla até estarem totalmente resfriadas para os ensaios de resistência à compressão.

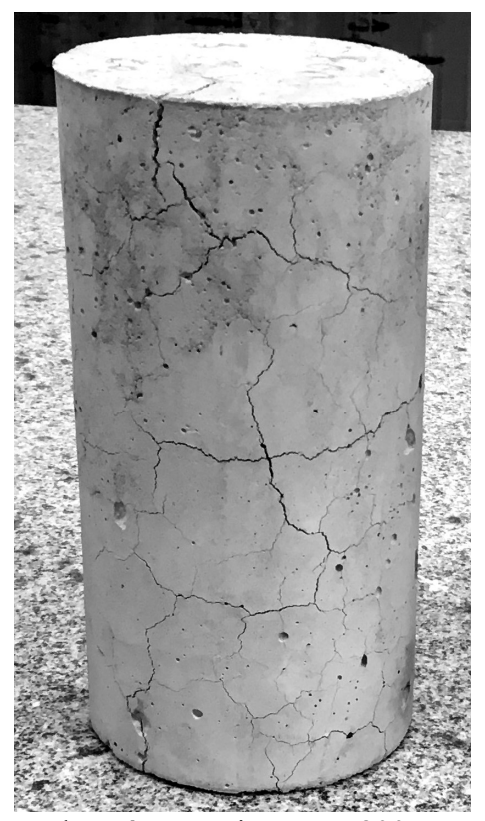

Figura 7: Amostra fissurada após aquecimento a $800^{\circ} \mathrm{C}$ e resfriamento com $\mathrm{CO}_{2}$

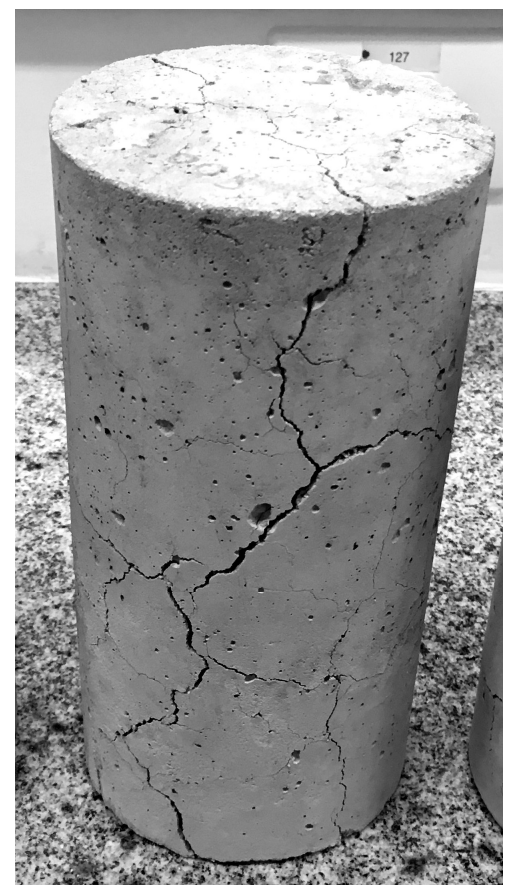

Figura 8: Amostra fissurada após aquecimento a $800^{\circ} \mathrm{C}$ e resfriamento natural

Os corpos de prova aquecidos a $800^{\circ} \mathrm{C}$ e resfriados com água apresentaram fissuras, mas estas não aumentaram com o tempo, parecendo cicatrizadas, como mostrado na figura 9. Esse efeito de cicatrização se refere à reação do dióxido de carbono com o hidróxido de cálcio presente no concreto. 

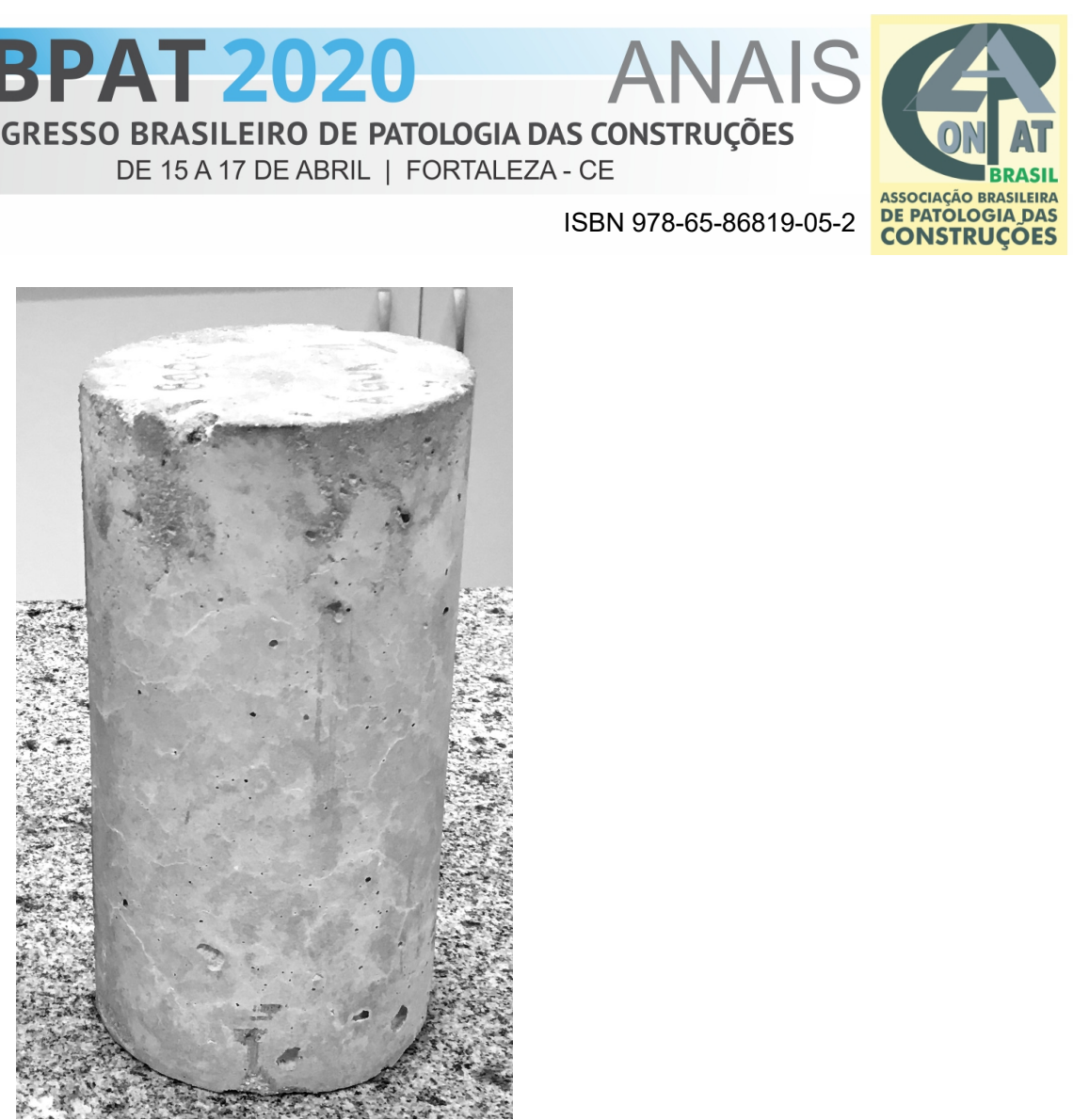

Figura 9: Amostra após aquecimento a $800^{\circ} \mathrm{C}$ e resfriamento com água

Após a ruptura das amostras, verificou-se visualmente que nenhuma amostra apresentou ruptura no agregado graúdo, e que para os corpos de prova aquecidos a $800^{\circ} \mathrm{C}$, conseguiu-se quebrar o concreto facilmente com as mãos. A ruptura ocorreu na zona de transição entre a pasta de cimento e o agregado, como mostrado na figura 10, indicando perda de aderência e confirmando a fragilidade dessa região devido à desidratação e consequente retração da pasta e expansão do agregado graúdo, conforme exposto por Fernandes et al. (2017).

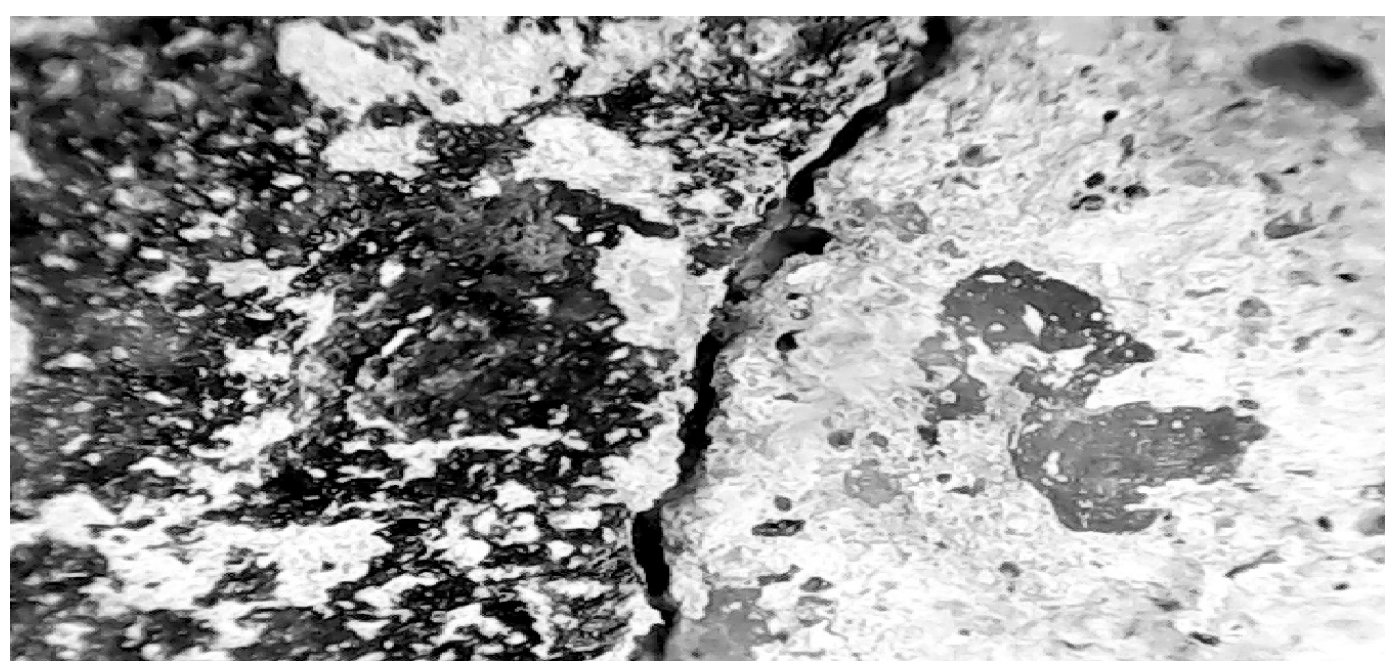

Figura 10: Fissura na zona de transição de uma amostra aquecida a $600^{\circ} \mathrm{C}$ e resfriada com água

\section{CONCLUSÃO}

Com o presente estudo foi possível verificar que o resfriamento do concreto com a utilização de água não representou maior perda de resistência nos corpos de prova nas condições analisadas, assemelhando-se aos resultados obtidos por Sousa (2009). Havendo um indício de que a água pode auxiliar na cicatrização de fissuras do concreto, visto que as amostras resfriadas à temperatura ambiente apresentaram maiores perdas na resistência para as três temperaturas analisadas. 
Pode-se considerar que as amostras retiradas da mufla para resfriamento lento também foram expostas ao choque térmico, pois foram retiradas de temperaturas de $400^{\circ} \mathrm{C}, 600^{\circ} \mathrm{C}$ e $800^{\circ} \mathrm{C}$ para temperatura ambiente, que esteve entre $14^{\circ} \mathrm{C}$ e $21^{\circ} \mathrm{C}$ nos dias dos ensaios. A utilização de carga de gás carbônico demonstrou um método de resfriamento mais próximo ao natural, pois apesar da baixa temperatura do gás, não foi o suficiente para resfriar os corpos de prova. Estatisticamente, os métodos utilizados para resfriamento não demonstraram ter influência na resistência residual das amostras. Ao contrário do aumento da temperatura, que apresentou ter efeito na diminuição da resistência do concreto.

A falta de padronização nas pesquisas conduzidas nessa área demonstra uma dificuldade de se comparar resultados. Além disso, a diversidade e peculiaridade das situações de incêndio em edificações também apresentam uma dificuldade em conduzir ensaios que representem a realidade.

\section{REFERÊNCIAS}

ASSOCIAÇÃO BRASILEIRA DE NORMAS TÉCNICAS. NBR 14432: Exigências de resistência ao fogo de elementos construtivos de edificações - Procedimento. Rio de Janeiro, 2001.

FERNANDES, B. et al. Microestrutura do concreto submetido a altas temperaturas: alterações físico-químicas e técnicas de análise. RIEM - IBRACON Structures and Materials Journal, [S.1.], v. 10, n. 4, p. 838-863, ago. 2017.

LORENZON, A. Análise da resistência residual do concreto após exposição a altas temperaturas. 2014.102 f. Trabalho de Conclusão de Curso (Engenharia Civil) - Departamento Acadêmico de Construção Civil da Universidade Tecnológica Federal do Paraná. Pato Branco, 2014.

MEHTA, P. K.; MONTEIRO, P. J. M. Concreto: microestrutura, propriedades e materiais. São Paulo, SP. IBRACON, 2008.

PARANÁ. Corpo de Bombeiros Militar do Paraná (CBPMPR). Norma de Procedimento Técnico 003: Terminologia de segurança contra incêndio. Versão 03, out. 2014. 49 p.

SEITO, A. I. et al. (Ed.) A Segurança Contra Incêndio no Brasil. São Paulo: Projeto Editora, 2008.

SILVA, D. S. Propriedades mecânicas residuais após incêndio de concretos usados na construção civil na grande Florianópolis. 2009. 102 f. Dissertação (Mestre em Engenharia) - Programa de Pós-Graduação em Engenharia Civil da Universidade Federal de Santa Catarina. Florianópolis, 2009.

SILVA, V. P. Sobre o coeficiente $\gamma_{S 1}$ do método do tempo equivalente para a determinação do tempo requerido de resistência ao fogo das estruturas. Revista Minerva - Pesquisa e Tecnologia, v. 5, n. 3, p. 315-321, dez. 2008.

SOUSA, M. M. Estudo experimental do comportamento mecânico e da microestrutura de um concreto convencional após simulação das condições de incêndio. 2009. 126 f. Dissertação (Mestrado em Construção Civil) Escola de Engenharia da Universidade Federal de Minas Gerais, Belo Horizonte, 2009. 